\title{
Developing Suitable Sensitive Compound Semiconductor Materials Doped by Transition Metals for Occupational Thermoluminescence Dosimetry
}

\author{
Salahuddin M. Kamal \\ Physics Department, Faculty of Science, King Abdulaziz University, Jeddah, K.S.A. \\ Email: smkahmad@kau.edu.sa, egykamal@yahoo.com \\ Received 13 February 2016; accepted 9 April 2016; published 12 April 2016 \\ Copyright (C) 2016 by author and Scientific Research Publishing Inc. \\ This work is licensed under the Creative Commons Attribution International License (CC BY). \\ http://creativecommons.org/licenses/by/4.0/

(c) (i) Open Access

\begin{abstract}
The essential objective of radiation dosimetry is to develop suitable sensitive materials for different measurements in radiation fields. Our exploration is to find potentially suitable high gamma radiation dosimeters in the range from $0.5 E 4$ to $1.5 \mathrm{E} 4 \mathrm{~Gy}$. Gamma rays source $\left({ }^{60} \mathrm{Co}, 136\right.$ Gy/min) has been used. Many compound semiconductor materials were prepared and investigated. Thermoluminescence (TL) glow curve was analyzed into its component by analytical segregation program using computerized glow curve deconvolution (CGCD). Three zero dose readings for non-irradiated powders of the materials have been taken as lower limit of detection. The results indicated that some of the tested materials have exhibited TL linearly with respect to dose. In addition, dose response of these materials was found to be useful for high radiation dosimetry. Glow curve structures exhibited several peaks corresponding to the various energies of the emptied traps. Variation in the standard deviation for reusability cycles has been notived after ten readout. The fading at ambient temperature was studied up to 60 days which reached a relative stability ( $1.5 \%$ for all), 10 days after irradiation. A typical glow curve of CoPa which irradiated with 1.5E4 Gy was analyzed. Characterizations of tested materials indicated that crystals of ZnLa:Li, ZnLa:Cd, and ZnLa:Cr have stable and increasing thermoluminescent responses with high gamma radiation dose range. Special glow peaks can be used as estimators for absorbed doses as well as re-estimation for time elapsed exposures.
\end{abstract}

\section{Keywords}

Doped Semiconductor Materials, Thermoluminescence Glow Curve Analysis, Occupational Dosimetry, High Gamma-Ray Dose 


\section{Introduction}

Optimization principle of radiation protection recommends steps to be taken in minimizing the harm risk. It is important to assess potential of high exposure of workers in radiation areas. Therefore, the main objectives of radiation dosimetry are in developing suitable materials for different radiation fields and for applying in practical situations [1]. These materials can be fixed to monitor and record the doses. Most occupational dosimetry systems use commercial or natural materials with near unity energy response in order to simplify the analysis of data [2]. Performance of occupational radiation dosimeters is generally assessed in terms of its operational efficiency range. Single personal dosimeter is not enough for all components of occupational effective dose for measuring the biological effect of ionizing radiation [3]. On the other hand, several materials were found to be suitable for personnel dosimetry which exhibiting intense thermoluminescence (TL), especially when doped with rare earths.

Doped or undoped semiconductors crystals as TL materials are not yet clear and need to be investigated in more details. Intensive experimental investigations have estimated the TL properties after interaction with various types of radiation fields. Properties of TL materials are dependent not only on applied radiation and thermal treatments but also on the selective incorporation of impurities. Many attempts have been made by many authors to study the effect of impurities in the semiconductor material used and their associated properties, as well as, the impact of energy deposited in the material due to thermal treatment and/or radiation fields [4]-[6]. Other studies of the TL of single crystals of (Te) doped with (Al or $\mathrm{Ga}$ ) and (Cd, $\mathrm{Zn}, \mathrm{Se}$ ) impurities are compared with TL of single crystals which were not doped [7]-[9]. Also, thermoluminescent emission by incorporated phosphor atoms is studied in the case of a single type of electron traps and recombination levels [10] [11].

The double salt, $\mathrm{CsMgI}_{3}$, appeared to be a semiconductor with a wide band gap (4.8 eV) [12]-[14]. The introduction of trivalent impurities $\left(\mathrm{Se}^{3+}, \mathrm{In}^{3+}, \mathrm{Ce}^{3+}, \mathrm{Gd}^{3+}, \mathrm{Ho}^{3+}, \mathrm{Er}^{3+}\right.$, and $\mathrm{Tm}^{3+}$ ) results in luminescent centers which are excited by irradiation at energies slightly below the band gap. It is found when these doped crystals are irradiated at low temperatures, they store energy and show pronounced TL [10].

Semiconductors vary in their ionizing radiation sensitivity according to the nature of the material, the type, and the concentration of inorganic impurities added to them [11]. Transition metals in semiconductors have a role as impurities for deep centers in semiconductors processing [15]-[19]. Identification of the defect is associated with particular TL peaks. The proper annealing treatment of these materials will be the ground for modification and selection of the semiconductor material as new highly sensitive TL materials-highly radiation dosimetries [5]-[6].

Computerised glow curve deconvolution (CGCD) methods have been used by physicists to study TL and thermoluminescence dosimetry (TLD) mechanisms for two decades [4] [20]-[27]. Many parameters can be extracted through this program for thermoluminescent materials especially for LiF:Mg,Ti (TLD-100), such as, fading corrections, estimation of elapsed time following accidental exposure, high dose measurements, and optimal annealing procedures.

In this study, several prepared compound semiconductor materials were prepared using Vertical Bridgeman technique crystal growth to explore their thermoluminescent characteristics as high gamma dosimeters. Industrial ${ }^{60} \mathrm{Co}$ gamma rays unit giving a dose rate of $136 \mathrm{~Gy} / \mathrm{min}$ has been chosen as a source for irradiation of doped elemental compounds to test their dosimetric potential.

\section{Materials and Methods}

\subsection{Sample Preparation}

Class of compound semiconductor materials have been prepared by combination using the mole-by-mole technique from group III-V materials, with either the group-III element replaced by a combination of group-II and group-IV elements, or the group-V element replaced by a combination of group-IV and group-VI elements. It should be emphasized that there may be more than one component to any of the three groups. For example, given group-II atoms $\mathrm{Zn}, \mathrm{Cd}$, group-IV atoms $\mathrm{Si}$, Ge, and group-V atoms $\mathrm{P}$, As, one could form the compound from a series of elements. Moreover, combinations of the two types of materials may also be considered in epitaxial growth. Table 1 illustrates semiconductors and compound semiconductor materials that were obtained to explore as high gamma radiation dosimeters. Compounds of lanthanum (La) and transition metals were prepared, where the compounds of CoLa, NiLa, CuLa, and ZnLa were doped each with $\mathrm{Li}$, Cd and Cr. The crystal growth 
Table 1. Semiconductor and compound semiconductor materials preparation of a compound semiconductor doped by transition metals.

\begin{tabular}{|c|c|c|c|c|c|c|}
\hline $\begin{array}{l}\text { Transition } \\
\text { elements }\end{array}$ & $\begin{array}{c}\text { Protactinium } \\
\text { Pa }\end{array}$ & $\begin{array}{c}\text { Sodium } \\
\mathrm{Na}\end{array}$ & $\begin{array}{c}\text { Lanthanum } \\
\text { La }\end{array}$ & $\begin{array}{c}\text { Lithium } \\
\text { Li }\end{array}$ & $\begin{array}{l}\text { Cadmium } \\
\text { Cd }\end{array}$ & $\begin{array}{c}\text { Chromium } \\
\text { Cr }\end{array}$ \\
\hline Cobalt (Co) & $\mathrm{CoPa}$ & $\mathrm{CoNa}$ & CoLa & CoLa:Li & CoLa:Cd & CoLa:Cr \\
\hline Nickel (Ni) & $\mathrm{NiPa}$ & $\mathrm{NiNa}$ & NiLa & NiLa:Li & NiLa:Cd & NiLa:Cr \\
\hline Copper (Cu) & $\mathrm{CuPa}$ & $\mathrm{CuNa}$ & $\mathrm{CuLa}$ & CuLa:Li & CuLa:Cd & CuLa:Cr \\
\hline Zink (Zn) & $\mathrm{ZnPa}$ & $\mathrm{ZnNa}$ & $\mathrm{ZnLa}$ & ZnLa:Li & ZnLa:Cd & $\mathrm{ZnLa}: \mathrm{Cr}$ \\
\hline
\end{tabular}

of these compounds was carried out using Vertical Bridgeman growth method under varying temperature gradients and at a vacuum of up to $10^{-3}$ torr. The method depends on epitaxy technique.

\subsection{Samples Preparation for Irradiation and Readout}

All samples are packaged in polyethlyne capsule and each group is packaged in a small envelope before irradiation. All samples were left 24 hours before TL reading. The weight of each sample was $20 \mathrm{mg}$ for each reading.

\subsection{Sample Irradiation}

The prepared materials have been exposed to gamma radiation in the range of 0.5 - $1.5 \mathrm{Mrad}$ (0.5E4 - 1.5E4 Gy). The irradiation has been carried out at the National Center for Radiation Research and Technology of the Egyptian Atomic Energy Authority (EAEA). At room temperature and atmospheric pressure, industrial 60Co gamma rays unit with dose rate of $136 \mathrm{~Gy} / \mathrm{min}$ was utilized to irradiate the samples at different doses.

\subsection{TLD System Harshaw/Filtrol's TLD System 4000}

An advanced-design system for manual evaluation of thermoluminescent dosimeters, namely Harshaw/Filtrol's TLD system 4000, which was used to evaluate the TL reading versus used dose. TLD SYSTEM 4000 evaluates and identifies TLD materials using highly flexible dosimeter heating profile repertories and incorporates. A user friendly menu-driven parameter and readout selection method is tailored to the application. A choice of two operating modes can be used: Production Mode for routine evaluation of TLD materials; and Research Mode for maximum flexibility of parameter selection and display.

The system has a precision temperature controller, which insures a high degree of accuracy and reproduction. Read time can be controlled from 10 to 300 second. Rapid, accurate, linearly ramped heating to a maximum of $400{ }^{\circ} \mathrm{C}$ in the bulk drawer, and $300{ }^{\circ} \mathrm{C}$ in the card drawer is insured by a platinum heating element with a welded thermocouple. A stable reference light source, consisting of ${ }^{14} \mathrm{C}$ activated $\mathrm{CaF}_{2}$ : $\mathrm{Eu}$, is located in the drawer. The system was calibrated in nanocolunb (nC) for specified doses in Rads with irradiated LiF-100 samples.

The accuracy and sensitivity of TLD counting system were continuously checked during the whole period of the experimental measurements of 6 months. The ${ }^{90} \mathrm{Sr}$ source of 30.2-year half-life is fixed inside the TLD system.

\subsection{Glow Curve Analyzer}

It displays the different parameters of the glow curve structure of the TL materials; heating rate, minimum and maximum heating temperature, acquisition time of heating, TL-readout in coulomb, and unit of dose in rad. The unit is corrected to the TL calibration factor "rad/coulomb".

\subsection{The Computerized Glow Curve Deconvolution}

The CGCD program gives six processes per curve; background subtraction only, peak 2 eliminated, peak separation with peak 2 eliminated, peak separation without peak 2 eliminated, gaussian peak estimation, and select another curve. Table 2 shows the steps of run program. 
Table 2. Harshow/Filtrol computerized glow curve deconvolution s-23259.003.

\begin{tabular}{|c|c|c|}
\hline CGCD file access & $\begin{array}{l}1=\text { Data file } \\
2 \text { = Selected curves } \\
\text { Enter choice }[1 \text { or } 2 \text { ]: } 1 \\
\text { Enter the name of the data file: } 1 \text {. dat }\end{array}$ & $\begin{array}{l}\text { Save results in long file } \\
{[\mathrm{Y} / \mathrm{N}]}\end{array}$ \\
\hline CGCD OPTIONS & $\begin{array}{l}\text { 1-Background subtraction only } \\
\text { 2-Peak } 2 \text { eliminated } \\
\text { 3-Peak separation with Peak } 2 \text { eliminated } \\
\text { 4-Peak separation without Peak } 2 \text { eliminated } \\
\text { 5-Gussian peak estimation } \\
\text { 6-Select another curve }\end{array}$ & \\
\hline Selection of deconvolution parameters & $\begin{array}{l}1 \text { = Mark initial parameters on graph } \\
2 \text { = Enter initial or fixed parameters } \\
\text { Enter your choice ( } 1 \text { or } 2 \text { ): } 1 \\
\text { How many peaks do you want to separated : }\end{array}$ & 1 \\
\hline
\end{tabular}

\section{Results and Discussions}

TL phenomenon now occupies a central and constantly expanding role in the dosimetry of ionizing radiation applications. Intensive experimental investigation has mapped out TL properties of many materials and their interaction with various types of radiation fields. Properties of TL materials are dependent not only on the incorporation of impurities, but also on the applied radiation and thermal treatments. In this study, groups of materials were prepared as compound semiconductors as illustrate in Table 1. Table 3 illustrates the thermoluminescent response of these materials that were irradiated using ${ }^{60} \mathrm{Co}$ gamma rays unit.

Three high doses 0.5E4, 1E4, and 1.5E4 Gy are selected. The results of irradiation indicated that some of the used compound semiconductor materials have shown linear thermoluminesce with these doses. Hence, these spicific responses indicated the feasibility of these prepared materials to act as high dose dosimeters. This indication was arrived from observation of the effect of dopant $\mathrm{Li}, \mathrm{Cd}$, and $\mathrm{Cr}$ on $\mathrm{TL}$ properties of the prepare compound semiconductor materials.

Preliminary characterization of theses materials indicated that crystals of $\mathrm{ZnLa}: \mathrm{Li}$, ZnLa:Cd, and ZnLa:Cr have stable linear thermoluminescent responses with gamma radiation dose in the tested rang. In particular, doping materials of ZnLa was found to be useful for high radiation dosimetry. The doping materials of ZnLa:Li and $\mathrm{ZnLa:Cd}$ gave the most sensitive responses.

Two investigations have been carried out for materials proposed as compound semiconductors:

1) Thermoluminescent characteristics:

\section{Dose response}

In the tested range, doping materials with $\mathrm{ZnLa}$ was found to be useful for high radiation dosimetry as shown in Figure 1. ZnLa:Li, ZnLa:Cd, and ZnLa:Cr may be selected as radiation dosimeters where they have high sensitivities and stable responses for high gamma irradiation doses. Analyses of the results showed that the instability of TLD reader due to the change of reading under the effect of room ambient temperature showed a statistical variance ranged over $\pm 1.3 \%$ with average error $\sigma \mathrm{TL}= \pm 1.7 \%$.

\section{Glow curve structures of prepared materials}

The obtained glow curves of tested materials exhibit several peaks corresponding to the various energies of the emptied traps as shown in Figures 2-5. The amplitude of each peak and the subtended area under the peak are approximately proportional to the trapped population and the absorbed dose.

\section{Reusability}

In Figure 1, the TL responses of the ZnLa:Li , ZnLa:Cd and ZnLa:Cr were obtained by measuring them ten times after repeated standard annealing and irradiation procedures. The standard deviations of $\mathrm{ZnLa}: \mathrm{Li}$, $\mathrm{ZnLa}: \mathrm{Cd}$ and $\mathrm{ZnLa}: \mathrm{Cr}$ after ten readout cycles were $\pm 46.83 \%, 12.3 \%$ and $15.3 \%$, respectively.

\section{Lower Limit of Detection}

The lowest detectable values for ZnLa:Li , ZnLa:Cd and ZnLa:Cr were 11.5, 6.76, and $2.31 \mathrm{mGy}$, respectively.

\section{Fading}

The fading at ambient temperature was studied up to 60 days. The TL response of ZnLa:Li, ZnLa:Cd and $\mathrm{ZnLa}$ :Cr showed a decrease (6.85\%, 6.9\% and 5.6\% respectively) after 3 hours of irradiation and then (18.5.0\%, 


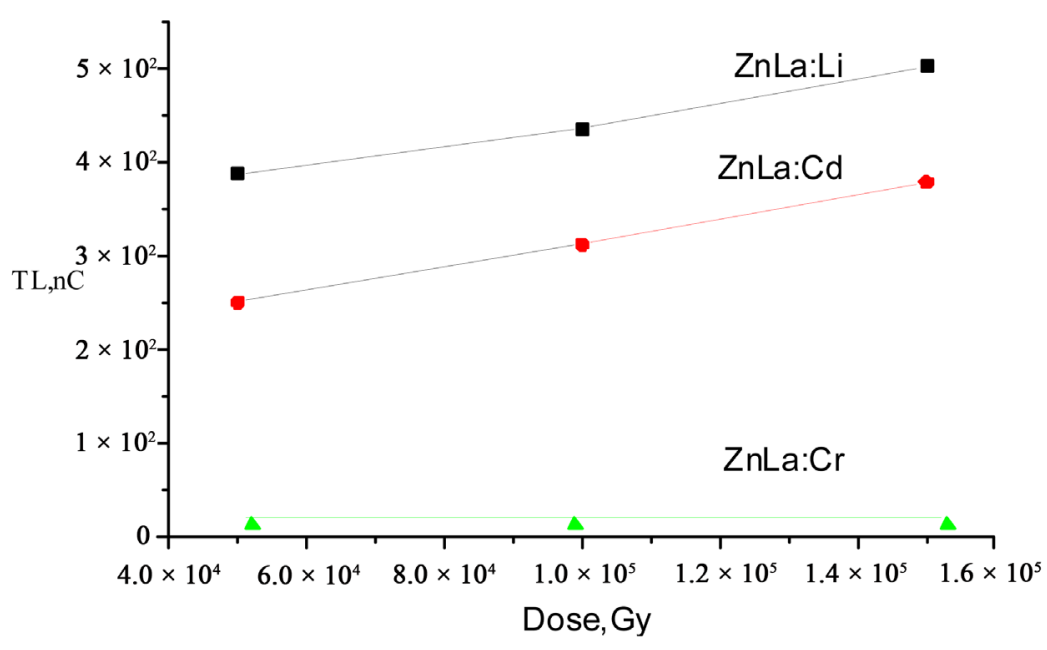

Figure 1. Illustrates TL in nC versus dose in Gy of selected material.

Table 3. TL response in (nC) of irradiated samples.

\begin{tabular}{|c|c|c|c|}
\hline Compound & 0.5E5 Gy & 1 E5 Gy & 1.5E5 Gy \\
\hline $\mathrm{NiPa}$ & 9.05 & 4.64 & 4.53 \\
\hline $\mathrm{CuPa}$ & 2.91 & 1.97 & 1.69 \\
\hline $\mathrm{ZnPa}$ & $\mathrm{x}$ & $\mathrm{x}$ & $\mathrm{x}$ \\
\hline $\mathrm{CoPa}$ & 13.5 & $2 . .1$ & 8.87 \\
\hline $\mathrm{NiNa}$ & 3.79 & 4.64 & 3.86 \\
\hline $\mathrm{CuNa}$ & 3.47 & $\mathrm{x}$ & $\mathrm{x}$ \\
\hline $\mathrm{ZnNa}$ & $\mathrm{x}$ & $\mathrm{x}$ & $\mathrm{x}$ \\
\hline CoLa & 9.05 & 2.54 & 3.13 \\
\hline NiLa & 2.78 & 3.69 & 1.69 \\
\hline CuLa & 18.9 & $\mathrm{x}$ & $\mathrm{x}$ \\
\hline ZnLa & $\mathrm{x}$ & $\mathrm{x}$ & $\mathrm{x}$ \\
\hline CoLa:Li & 7.72 & 7.46 & 5.09 \\
\hline NiLa:Li & 8.09 & 7.56 & 14.81 \\
\hline CuLa:Li & 3.79 & $\mathrm{x}$ & $\mathrm{x}$ \\
\hline ZnLa:Li & 388.10 & 435.94 & 503.83 \\
\hline CoLa:Cd & 7.72 & 7.92 & 6.44 \\
\hline NiLa:Cd & 10.61 & 12.51 & 12.49 \\
\hline CuLa:Cd & 13.33 & 12.19 & 20.21 \\
\hline ZnLa:Cd & 250.5 & 312.19 & 379.32 \\
\hline CoLa:Cr & 10.97 & 9.64 & 10.40 \\
\hline NiLa:CR & 10.33 & 52 & 79 \\
\hline CuLa:Cr & 182595.3 & 83685.36 & $\mathrm{x}$ \\
\hline ZnLa:Cr & 5.77 & 6.15 & 7.95 \\
\hline
\end{tabular}




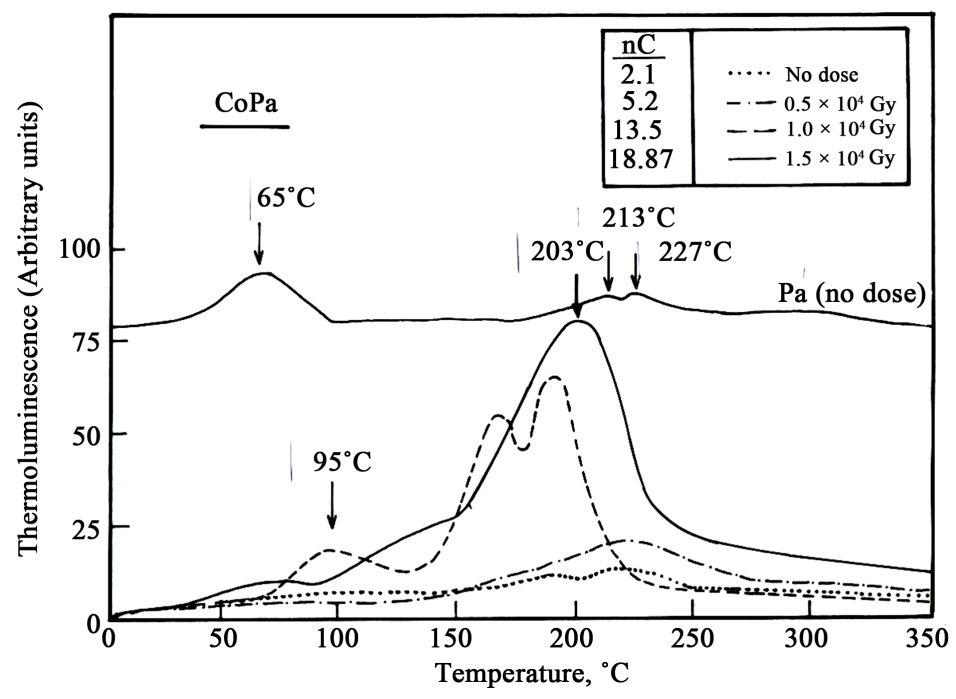

Figure 2. Thermoluminescent glow curves of gamma irradiation and unirradiated protactinium and cobalt-protactinium compound.

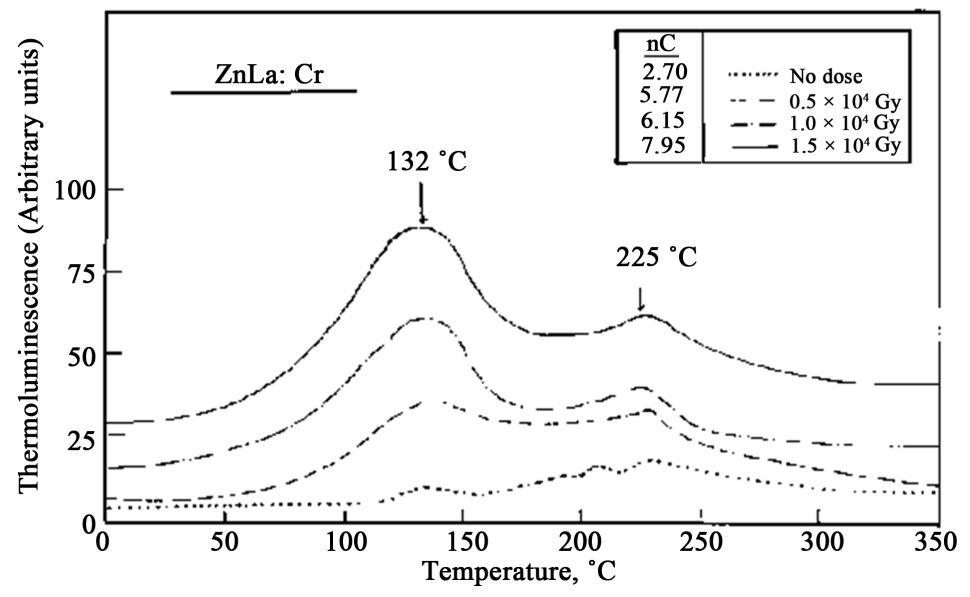

Figure 3. Thermoluminescent glow curves of gamma irradiation and un-irradiated zink-lanthanum compound doped with chromium (ZnLa:Cr).

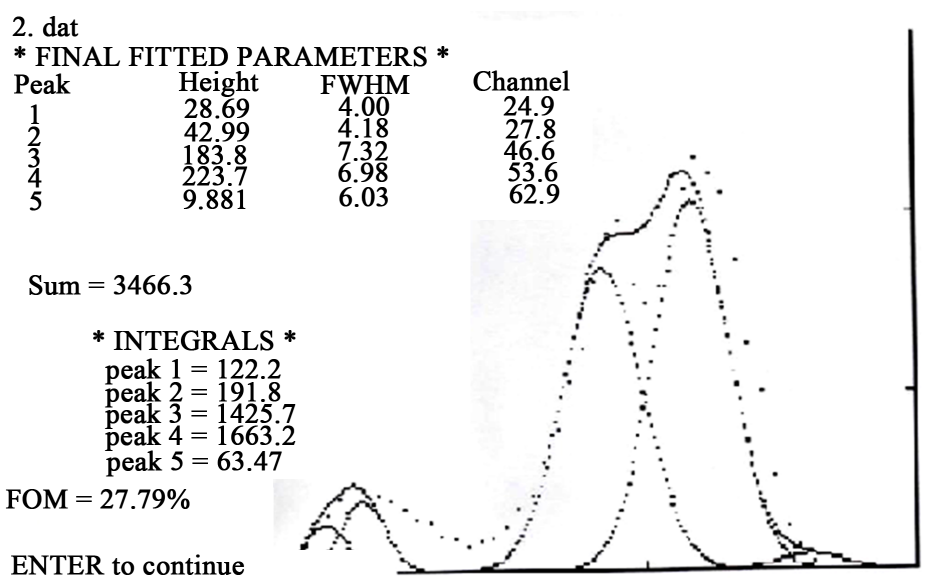

Figure 4. Glow curve analysis by CGCD program of CoPa sample (five first-order peaks). 


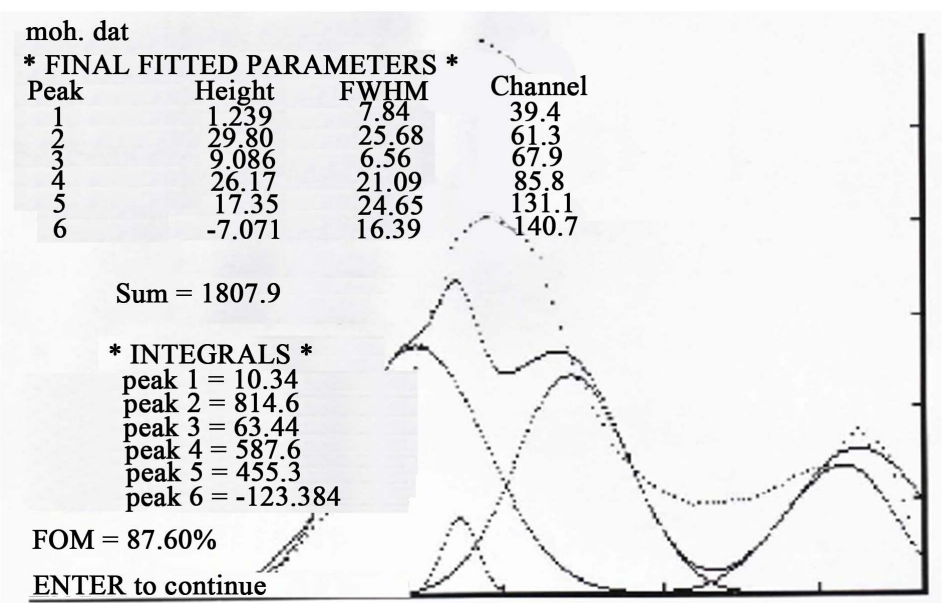

Figure 5. Glow Curve analysis by CGCD program of ZnLa:Cr sample (six firstorder peaks).

$15.0 \%$ and $10.5 \%$ respectively) after 24 hours, reaching a relatively stability ( $1.5 \%$ for all) 10 days after irradiation.

2) TL deconvolution

CGCD is the process of analytical segregating the TLD glow curve into its component glow peaks using first order kinetics algorithms. A typical glow curve of CoPa which irradiated with $1.5 \mathrm{E} 4 \mathrm{~Gy}$ is analyzed to its major component peaks. Deconvolution enables these peaks to be individually displayed, analyzed, and their areas quantified. Then, the absorbed dose patterns can be identified. A measure of the accuracy of deconvolution can be obtained by adding the areas under the peaks to reconstruct the composite glow curve.

The above test program was implemented to evaluate the characteristics of the obtained materials as thermoluminescent dosimeters. Characterization of the tested materials indicated that crystals of $\mathrm{ZnLa}: \mathrm{Li}, \mathrm{ZnLa}: \mathrm{Cd}$, and $\mathrm{ZnLa:Cr}$ have stable and increasing thermoluminescent response with gamma radiation dose range (0.5E4 1.5E4 Gy).

\section{Conclusions}

1. The effect of dopant $\mathrm{Li}, \mathrm{Cd}$, and $\mathrm{Cr}$ on TL properties was investigated. The results indicated the feasibility of some of these prepared materials to act as high dose dosimeters.

2. Preliminary characterization of tested materials indicated that crystals of $\mathrm{ZnLa}: \mathrm{Li}, \mathrm{ZnLa}: \mathrm{Cd}$, and $\mathrm{ZnLa}: \mathrm{Cr}$ have stable and increasing thermoluminescent response with gamma radiation dose range (0.5E4 - 1.5E4 Gy).

3. In particular, doping materials of $\mathrm{ZnL}$ were found to be useful for high radiation dosimetry.

Hence, based on the observations obtained in these experiments, it is suggested that the use of these selected compound semiconductor materials in potential high dose work places will help to predict and evaluate the possible worker exposures in their work places. These measurements will then be useful in better design of work procedures so as to minimize worker radiation exposure as recommended by national and international radiation protection regulations.

TL process was found to be best described by the first-order kinetics model used in CGCD program. A dependence of the glow curves on both type of dopant and photon absorbed dose was detected. Some glow results seem to be not correlated with absorbed dose probably due to growth conditions and dose homogeneity during irradiation. Finally, special glow peaks can be used to estimate both absorbed doses and time elapsed exposures.

\section{References}

[1] Susan, T. and Heather, O. (1997) Potential Radiation Exposure in Military Operations; Protecting the Soldier before, during, and after. National Academy Press, Washington.

[2] Rayes, I.M. and Stoebe, T.G. (1990) Personnel Dosimetry Badge System For Mixed Radiation Fields Based on Tef- 
lon-Embedded $\mathrm{CaSO}_{4}$ :Dy TLD Materials. Radiation Protection Dosimetry, 32, 5-13.

[3] Britcher, A.R., Bartlett, D.T. and Burgess, P.H. (1991) The Measurement of Occupational Exposure to External Radiation: Principles and Practice. Journal of Radiological Protection, 11, 185-190. http://dx.doi.org/10.1088/0952-4746/11/3/004

[4] Chen, R. (1984) Kinetics of Thermoluminescence Glow peaks. In: Horowitz, Y.S., Ed., Thermoluminescence and Thermoluminescent Dosimetry, CRC Press, Boca Raton, 49-88.

[5] Hennel, A.M. (1975) About Crystal Field Parameters of Transition Metal Impurities in Semiconductors. Physica Status Solidi, 72, K9-K12. http://dx.doi.org/10.1002/pssb.2220720152

[6] Bavdaz, M., Kraft, S. and peacock, A. (1998) Compound Semiconductor Detectors for X-Ray Astronomy: Spectroscopic Measurements and Material Characterization. Material Research Society, 681, 565-572.

[7] Marczewska, B., Bilski, P., Gieszczyk, W., Kłosowski, M., Twardak, A. and Wróbel, D. (2015) Dosimetric Properties of Luminescence Crystals Grown by Micro-Pulling down Method. 5th European Conference on Crystal Growth, Bologna, 9-11 September 2015, 22.

[8] Bangaru, S., Revathi, P. and Muralidharan, G. (2013) Thermoluminescence, Optical Absorption and XRD Studies on Potassium Iodide Doped Zinc Nitrate Hexa Hydrate Single Crystals. Advances in Optoelectronic Materials, 1, 40-47.

[9] Chun-Kit, T. (2010) Defect Studies of Single Crystal and Thin Film Zinc Oxide by Positron Annihilation Spectroscopy and Cathodoluminescence. M.Sc. Thesis, The University of Hong Kong, Hong Kong.

[10] McPherson, G.L. and Talluto, K. (1982) Luminescent Centers in Doped Crystals of CsMgIi 3 : Energy Storage and Thermoluminescence. Solid-State-Communications, 43, 331-334. http://dx.doi.org/10.1016/0038-1098(82)90488-4

[11] Unlu, M.S., Piqueras, J., Kalkhoran, N.M. and Sekiguchi, T. (1999) Optical Microstructural Characterization of Semiconductors. Materials Research Society, Warrendale.

[12] Trinkler, L., Berzina, B.Auzina, A., Benabdesselam, M. and Iacconi, P. (2007) UV Light Energy Storage and Thermoluminescence in AlN Ceramics. Physica Status Solidi, 4, 1032-1035. http://dx.doi.org/10.1002/pssc.200673764

[13] McPherson, G.L. and Talluto, T. (1982) Luminescent Centers in Doped Crystals of CsMgI3: Energy Storage and Thermoluminescence. Solid State Communications, 43, 331-334. http://dx.doi.org/10.1016/0038-1098(82)90488-4

[14] Lukosz, W. and Meier, M. (1981) Lifetime of Luminescent Centers Close to Dielectric Interfaces and Metal Surfaces: Changes in Spontaneous Emission Probabilities, and Energy Transfer to Surface Plasmons. Journal of Luminescence, 24-25, 777-780. http://dx.doi.org/10.1016/0022-2313(81)90090-9

[15] Mishin, Y., Cowern, N.E.B., Catlow, C.R.A., Farkas, D. and Vogl, G. (2014) Diffusion Mechanisms in Crystalline Materials. Cambridge University Press, Cambridge.

[16] Silberberg, M. (1996) Chemistry: The Molecular Nature of Matter and Change. Mosby-Year Book, New York.

[17] Olmsted, J. and Williams, G.M. (1994) Chemistry: The Molecular Science. Mosby, New York.

[18] Balkanski, M. and Wallis, R.F. (2000) Semiconductor Physics and Applications. Oxford University Press, New York.

[19] Schulman, J.H. (1959) Solid State Dosimeters for Radiation Measurement. In: Marley, W.G. and Morgan, K.Z., Eds., Progress in Nuclear Energy, Pergamon Press, New York, 150-159.

[20] Becker, K. (1973) Solid State Dosimetry. CRC Press, Cleveland Ohio.

[21] Horowitz, Y.S. and Yossian, D. (1995) Computerised Glow Curve Deconvolution-Application to Thermoluminescence Dosimetry. Radiation Protection Dosimetry, 60, 1-114.

[22] Horowitz, Y.S. and Moscovitch, M. (1986) LiF-TLD in the Microgray Dose Range via Computerised Glow Curve Deconvolution and Background Smoot. Radiation Protection Dosimetry, 17, 337-342.

[23] Shachar, B.B. and Horowitz, Y.S. (1988) Dosimetric Characterisation of the High Temperature Peaks of LiF:Mg,Ti and $\mathrm{CaF}_{2}:$ Tm Using Computerised Glow Curve Deconvolution. Radiation Protection Dosimetry, 22, 87-96.

[24] Horowitz, Y.S. (1990) Study of the Annealing Characteristics of LiF:Mg,Ti Using Computerised Glow Curve Deconvolution. Radiation Protection Dosimetry, 33, 255-258.

[25] Yossian, D. and Horowitz, Y.S. (1996) Retrieval of Dosimetric Information from Distorted Glow Curves Using Computerised Glow Curve Deconvolution. Radiation Protection Dosimetry, 66, 75-78. http://dx.doi.org/10.1093/oxfordjournals.rpd.a031784

[26] Figel, M. and Sprunck, M. (1999) Fast Cooling and Computerised Glow Curve Deconvolution in Routine Personnel Monitoring with TLD-100. Radiation Protection Dosimetry, 81, 259-264. http://dx.doi.org/10.1093/oxfordjournals.rpd.a032592

[27] Udayashankar, N.K. and Bhat, H.L. (2001) Growth and Characterization of Indium Antimonide and Gallium Antimonide Crystals. Bulletin of Materials Science, 24, 445-453. http://dx.doi.org/10.1007/BF02706714 